\title{
Conexões
}

Artigo Original

\section{A autoscopia como método de autoanálise e feedback para bailarinos clássicos durante técnicas de pas de deux.}

Kaio César Celli Mota ${ }^{1}$

Odilon José Roble ${ }^{1}$

Fidel Machado de Castro Silva ${ }^{1}$

\section{RESUMO}

As principais correções no processo de movimentação técnica na dança partem, predominantemente, de uma figura externa conhecida como coreógrafo ou ensaiador. Propõe-se, com este estudo, o uso da autoscopia como método de autoanálise e auto-feedback em que o próprio bailarino realiza ao assistir a sua performance. Tal estudo constituiu-se a partir de filmagens de uma coreografia de pas de deux (dueto no balé clássico), com duas bailarinas diferentes e um mesmo bailarino, sendo que este possuia microcâmeras fixadas em seu corpo. Após o término da dança, cada bailarina foi convidada a verbalizar, individualmente, uma autoanálise. Posteriormente a esse momento, as bailarinas assistiram sua performance à partir das imagens capturadas pelas microcâmeras, análogas à visão do bailarino, sendo solicitado a cada bailarina que fizesse, novamente, uma autoanálise de sua performance. Foram comparadas as autoanálises realizadas sem e com o recurso da autoscopia. O objetivo foi interpretar se a autoscopia apresenta-se como um suporte eficiente no aprimoramento do processo de movimentação técnica na dança. Desse modo, após a intervenção realizada, observou-se que a utlização do método contribui para uma ampliação da percepção do movimento das bailarinas, devido ao recurso da videogravação que possibilita o desenvolvimento das capacidades de autoanálise e auto-feedback.

Palavras-Chave: Dança. Autoscopia. Pas de deux. Auto-análise.

\footnotetext{
${ }^{1}$ Universidade Estadual de Campinas

Recebido em: 16 nov. 2016

Aprovado em: 07 abr. 2017

Contato: kio_mota@hotmail.com

Conexões: Educ. Fís., Esporte e Saúde, Campinas: SP, v. 15, n. 2, p. 172-186, abr./jun. 2017. ISSN: 1980-9030
} 


\section{Autoscopy as self-analysis method and feedback to classical dancers in a pas de deux techniques}

\section{A BStract}

The main corrections, about the technical movement process in dance comes, mostly, from an external figure known as the choreographer or conductor. In this study it is proposed the use of autoscopy as a self-analysis method and self-feedback where the dancer performs himself to watch his performance. This study was made from shootings of a pas de deux choreography (duet in classical ballet), with two different ballerinas and one single male dancer which had micro cameras fixed on his body. After dancing, each dancer was invited to individually verbalize a self-analysis. Subsequent to this first moment, the dancers watched their performance from the images captured by the micro cameras, similar to the dancer's view, being requested to each dancer to make a second self-analysis of your performance. The self-analysis made with and without the use of autoscopy were compared. The purpose was to interpret if the autosocpia presents itself as an efficient support in the improvement on the technical movement process in dance. Thus, after the intervention, it was observed that using the method contributes to broadening the perception of motion of the dancers due to the video recording recourse that allows the development of self-analysis and self-feedback capacities.

Keywords: Dance. Autoscopy. Feedback. Pas de deux. Self-analysis.

\section{Autoscopía como un método de auto-análisis y retroalimentación para los bailarines clásicos durante técnicas de pas de deux}

\section{RESUMEN}

Las principales correcciones técnicas en el proceso de moverse en la pista salen predominantemente una figura externa conocida como coreógrafo o probador. Se propone este estudio, el uso de autoscopía como método de auto-análisis y auto-retroalimentación en el que la bailarina se produce a sí mismo para ver su actuación. Este estudio consistió en la filmación de una coreografía pas de deux (dúo en el ballet clásico) con dos bailarines diferentes y el mismo bailarín, y esto poseía microcámaras fijas en su cuerpo. Después del baile, cada bailarín fue invitado a verbalizar, cada uno, un auto-análisis. Con posterioridad a ese momento, los bailarines observaban su actuación a partir de las imágenes captadas por las cámaras micro, similar a la visión de la bailarina, y pidieron a cada bailarín que hacer de nuevo, un auto-análisis de rendimiento. las auto-análisis se realizaron en comparación con y sin el uso de autoscopia. El objetivo era interpretar el autoscopía se presenta como una ayuda eficaz en la mejora de los procesos técnicos del movimiento en la danza. Por lo tanto, después de las intervenciones, se observó que utlização método contribuye a ampliar la percepción del movimiento de los bailarines debido a la función de grabación de vídeo que permite el desarrollo de auto-análisis y capacidades de auto-retroalimentación.

Palabras Clave: Danza. Autoscopía. Pas de deux. Autoanálisis. 


\section{INTRODUÇÃO}

A autoscopia, processo no qual o sujeito, por meio de filmagens assiste a sua performance e se torna o agente de autoanálise e auto-feedback, surge na área da educação e vem apresentando resultados profícuos para a realização de uma reflexão sobre o próprio agir do sujeito. Ao aproximá-lo e utilizá-lo no campo da dança, propomos um processo de investigação no qual visamos adotar o método autoscópico (NAUTRE, 1989; SADALLA, 2004) como dispositivo de diagnóstico para os bailarinos do ballet clássico, mais especificamente, sobre as técnicas de pas de deux.

Ressaltamos que ao propor tal método, não estamos excluindo a função do ensaiador e corégrafo, durante o processo de construção do espetáculo, e sim o facilitando, uma vez que em níveis profissionais de dança, o bailarino, devido ao seu nível técnico, pode colaborar com possíveis correções técnicas e sensíveis da sua própria performance.

Ao escolhermos o ballet clássico e a técnica de pas de deux, reforçamos a sua importância e relevância histórica. O ballet clássico possui como gênese o interior dos palácios europeus com o intuito de representar a vida da aristocracia da época. A prática diferenciava-se da dança dos plebeus (que mais tarde, na historia da dança, originará as chamadas danças populares e folclóricas).

Nos grandes bailes, a dança passa a representar a maioria dos espetáculos dentro da corte. Na Itália do século XVI, a Rainha Catarina de Médici organiza o primeiro "Balé Cômico da Rainha", o que inicia a popularização e a difusão da prática entre a aristocracia. Posteriormente, surgem as escolas de dança, até a consolidação do ballet clássico e suas diferentes metodologias.

O pas de deux, como nós conhecemos atualmente, passou por diversas mudanças. Do homem que se transvestia para dançar, da mulher que era apenas plateia até a sua incorporação na dança, inaugurada pela entrada e profissionalização da bailarina Lafontaine (1655-1739).

No inicio do século XVIII, aparece pela primeira vez em publico, um casal dançando juntos, por vezes de mãos dadas, por vezes separadas. Desse modo, apresentase o inicio do pas de deux que culmina em seu desenvolvimento (incluindo um contato mais intimo dos bailarinos) para a prática que conhecemos hoje. A partir desses pontos, acreditamos que a autoscopia possa vir a ser um processo válido a ser adotado no campo da dança, uma vez que o processo de autoanálise e auto-feedback pode colaborar na ampliação da percepção corporal do bailarino possibilitando uma maior conscientização dos seus movimentos e um ganho na plasticidade e expansão estética da cena. 


\section{Algumas palavras sobre o balé clássico e a cinestesia}

A dança acompanha o homem desde o primórdio das suas aparições e organizações sociais. Já foi registrado, por diversos autores, que os seres humanos dançavam. Com o decorrer da história e o aparecimento do cristianismo durante a idade média, a dança sofre uma diferenciação quanto à divisão de classes. A aristocracia deixou de dançar a dança dos "pobres", passando a elaborar regras palacianas e cortesãs, de modo que deixasse a rigidez e vigorosidade aplicada à dança dos pobres, para que então pudesse ser dançada por eles.A dança (dentro dos palácios) passa por adaptações, de modo que representasse a vida da aristocracia. Surge então alguns movimentos, como o minueto, a galharda, a pavana e a volta, por exemplo.

O termo ballet apresenta-se como uma palavra francesa, derivada de ballare, que significa dançar, bailar. O ballet clássico foi criado então a partir das danças da corte. Com origem na Itália, na época da Renascença, o balé clássico surge como forma dos senhores aristocratas imitarem antigos imperadores romanos. Da rua para pequenos bailes, o balleto passa por uma sistematização do ensino com variações de posições de cabeça, tronco, braços e pés, nascendo então à escola italiana de balé difusora do ensino dessa dança por toda a Europa (CAMINADA, 1999).

No ballet, o pas de deux, significa, em francês, "passo de dois". Representado por dois bailarinos, uma mulher e um homem, ele revela grande significância no campo da dança desde os seus primórdios até os dias de hoje. Surge pela primeira vez, como já abordamos, no inicio do século XVIII, um casal dançando junto em um espetáculo executando os mesmos passos, o pas de deux (GRESKOVIC, 2005). O pas de deux passa a demostrar, essencialmente, a paixão e o amor, retratado por expressões e sentimentos afetuosos entre seus parceiros románticos (COHEN, 2004).

No final do século XVIII e inicio do século XIX, os bailarinos começam a desenvolver um contato físico mais próximo, revelando com o passar do tempo o pas de deux que conhecemos atualmente. Partindo para uma perspectiva atual $\mathrm{e}$ profissionalizante da dança, ao se apresentar um pas de deux, surge a necessidade de ensaios, que é o tempo reservado para o aprimoramento da coreografia e da técnica. Para tal, existe a figura do ensaiador, que surge no âmbito da dança e do teatro como a figura externa ao elenco responsável pelo ensaio, tendo em vista um espetáculo. Essa figura ganha destaque ao longo do tempo, principalmente dentro de grandes companhias. Ela surge ao lado do coreógrafo, como aquele que conhece a coreografia, que respeita a sua obra e que dá unidade ao grupo.

Ao escolhermos o pas de deux como objeto de análise, acreditamos pelo exposto, termos uma pequena amostra, fidedigna a respeito da arte do balé clássico, uma vez que ele ainda tende a afirmar o tradicionalismo da causa clássica, respeitando suas origens e convicções. Grandes companhias, ao redor do mundo, apresentam anualmente 
grandes espetáculos de ballet (Quebra Nozes, Bela Adormecida e Lago dos Cisnes, por exemplo), que respeitam todo o virtuosismo da dança e mantém a técnica empregada antigamente, dando continuidade às tradições do ballet clássico.

A cinestesia é definida como uma experiência corporal, uma consciência íntima que apenas nós mesmos podemos ter do nosso corpo e, desenvolvemos a partir dele uma noção espacial e dinâmica (MARZANO, 2007). Esta experiência esta relacionada com a ação, desta forma, a percepção de um ato voluntario é uma experiência corporal.

A cinestesia fornece informações acerca da posição do corpo no que se refere à direção, à extensão e à velocidade dos movimentos e do nível da tensão muscular. Assim, ao propormos a autoscopia como método de intervenção que busca uma melhora na percepção e no movimento da bailarina, não podemos deixar de considerar uma melhora no perfil cinestésico, haja vista que tal perfil está relacionado ao movimento, às relações neuro-musculares e às percepções corpo $\mathrm{x}$ espaço do próprio sujeito e dos demais corpos presentes em cena (FERREIRA, 2000).

\section{Autoscopia como uma estratégia de ampliação da percepção de si do bailarino}

Quando dançamos as principais correções, análises técnicas, críticas e sugestões partem de uma figura externa conhecida como coreógrafo ou ensaiador. Esta figura possui uma importante função antes, durante e após a performance dos bailarinos. $\mathrm{O}$ desempenho em cena, demanda uma série de sugestões e correções apresentadas em momentos de ensaio ou posterior à apresentação como forma de feedback direto aos bailarinos. Todos esses elementos representam estratégias adotadas pelo coreógrafo e/ou ensaiador, como forma de melhorar a atuação do profissional em cena. Contudo, há ainda a dificuldade desse bailarino ser o sujeito da sua própria análise, aquele que realiza um auto-feedback e, assim, consegue identificar melhor sua performance no que diz respeito à questões técnicas. Evidentemente, a propriocepção de seus movimentos é um dado essencial e, de modo algum, insubstituível. Ao pensarmos em recursos externos para essa autoanálise, estamos nos esforçando no sentido de ampliar as formas de percepção e a utilização de novas possibilidades.

Existe um grande desafio proveniente do questionamento: "como ensinar um bailarino a ter consciência do seu próprio movimento?" e, nesse sentido, propomos a investigação de uma técnica chamada de autoscopia como uma possibilidade a mais de somar esforços para a diminuição de tal dificuldade. Essa técnica vem obtendo bons resultados em campos distintos, especialmente na educação.

A autoscopia pode ser usada no processo de formação de professores com o objetivo de oferecer uma reflexão sobre as práticas pedagógicas e uma visualização do comportamento dos alunos em formação (NAUTRE, 1989). Entretanto, após realizada uma busca exploratória em periódicos especializados, não encontramos nenhuma pesquisa que se utilize desse método no campo da dança. Tal lacuna nos incentivou a 
prosseguir com o propósito do presente texto, pois acreditamos que a aproximação do método autoscópico à seara da dança poderá contribuir de maneira positiva. Ademais, ampliará os caminhos e as estratégias que facilitam e melhoram a performance do bailarino que passará a assumir o papel ativo de sujeito crítico quanto a sua performance. Dada essa autonomia ao bailarino, o coreógrafo e/ou ensaiador reduzirá a sua função de correção de movimentos e poderá dedicar-se com mais afinco às minúcias da criação e produção do espetáculo.

A palavra autoscopia é composta por dois termos: "auto" e "scopia" (o primeiro diz respeito a uma ação realizada pelo próprio sujeito, e o segundo vem do grego skoppós que quer dizer objetivo, finalidade, meta, alvo ou mira $)^{2}$. Nesse sentido, o sujeito da pesquisa autoscópica é o agente ativo que analisa e julga a sua própria performance. Esse procedimento é feito por meio de videogravações de um ou mais sujeitos, em determinadas situações para posterior autoanálise da atuação.

A vídeogravação é utilizada para entender o(s) autor(es), o cenário e a trama que os rodeia, sendo que as sessões de análise são realizadas posteriormente às cenas gravadas. Lembrando que o auto-feedback das ações e a reflexão sobre elas são os princípios mais importantes do estudo, não havendo julgamento externo sobre a avaliação do sujeito em termos de correta ou incorreta, mas sim em termos de validade. Essa validade corresponde diretamente à aplicação correta do método, ou seja, o que importa é que o sujeito tenha sido submetido a um procedimento mais isento de interferências externas possíveis, deixando sua avaliação mais próxima de uma expressão individual.

Esse procedimento é ainda bastante recente, mas já encontrado em alguns estudos(LINARD, 1974; NAUTRE, 1989; FERRÉS, 1996), que falam sobre a avaliação de si com imagens suas na tela. Todos esses autores focam no retorno da informação, quando o sujeito se assiste, virando o próprio objeto de feedback visual. A proposta é de se trabalhar com uma ideia de vídeo espelho, pois as imagens permitem potencializar a função da auto-avaliação, e ampliar o confronto "sujeito x sua imagem na tela", em que, no nosso recorete, o bailarino consegue identificar todo o seu potencial reflexivo e expressivo (FEREÉS, 1996). "No vídeo, a pessoa pode contemplar-se a partir de infinitos pontos de vistas" ( FERRÉS, 1996).

O procedimento autoscópico apresenta algumas vantagens, como nos vídeos, o material pode ser exibido no ritmo normal, acelerado ou pausado, possibilitando a percepção de detalhes que poderiam passar despercebidos e elementos minuciosos que, a priori, não seriam captados por uma observação direta e sem o auxílio dos recursos visuais. Ademais, propicia um distanciamento emotivo para a análise reflexiva do material registrado e também oferece condições de uma análise crítica, permitindo exercitar uma intensa atividade intelectual. 
Todavia, o método também apresenta desvantagens. A câmera, por exemplo, pode passar de um elemento neutro do estudo para um que exerce mudanças no ambiente e no objeto que, no nosso recorte, se revela pela figura do bailarino pesquisado. A filmagem pode causar certa ansiedade no indivíduo quando esse se vê em ação, gerando provavelmente uma recusa em se ver e, assim, exercer influência externa direta. Fator esse que distanciaria a característica de uma ação individual, como já mencionamos anteriormente. Tais pontos são destacados, concluindo que esses aspectos influenciam de forma direta nos resultados da pesquisa, quando dizem respeito a autoanálise e auto-feedback do sujeito pesquisado (FEERÉS, 1974; NAUTRE, 1989). Ressaltamos que os aspectos supracitados foram considerados em nossa intervenção

Nossa proposta utilizou o método durante o momento dos ensaios para analisar se, se ao propiciar ao bailarino, por meio do recurso da autoscopia, a realização de uma análise técnica, reflexiva e expressiva, quanto à sua performance há alterações e contribuições para a melhora e ampliação dos gestos e, consequentemente da cena. Pensamos que tal processo possa auxiliar e facilitar o trabalho de corégrafos, ensaiadores e professores de dança, pois pode promover uma ampliação da percepção do corpo e dos gestos do bailarino.

Além da questão da autoanálise e auto-feedback, esse processo talvez permita ao sujeito entender e ter consciência do seu próprio movimento, reconhecendo princípios da técnica, falhas gestuais, a gênese da relação "passo/sequência/movimento" e a correta ou "ideal" finalização de um passo ou proposta coreográfica. No mais, é também indiscernível a questão da consciência corporal e imagem de si, inevitavelmente tensionadas quando o sujeito vê a si mesmo em vídeo.

\section{Objetivos}

Este estudo teve como objetivo: analisar se o método da autoscopia aplicado a bailarinos clássicos em situação de pas de deux oferece recursos efetivos para a conscientização do próprio movimento, por meio da autoanálise e construção de autofeedback.

\section{Materiais e Métodos}

Para o método de intervenção, escolhemos a coreografia "Pas de Paysant" do Balé de repertório Giselle, tradicional obra francesa do compositor de Ópera, Adolph Adam, que é um balé romântico dançado pela primeira vez em Paris em 1840. 
A história se passa em uma aldeia, em que a jovem Giselle vive. A mesma se apaixona por um nobre, disfarçado de camponês (príncipe Albrecht) e, quando descobre a verdade, com a saúde muito debilitada, vem a morrer. Durante o primeiro ato, acontece o pas de deux, coreografia em que os dois aldeões convidados por Giselle dançam para o rei e a Rainha que vêm, porventura, visitar a pequena aldeia. Tal coreografia foi adotada como recorte de estudo, pois dentro de uma perpectiva clássica é uma das que apresenta niveis de dificuldades técnicos menos complexos quando comparada com as demais obras de ballet clássico de repertório.

O pas de deux acima mencionado possui, aproximadamente, 3 minutos e 40' segundos (sem contar a variação feminina e masculina). Ele foi previamente ensaiado com duas bailarinas e depois foi feito o processo da autoscopia.

$\mathrm{Na}$ obra tradicional, a mulher dança com a sapatilha de ponta, porém como trabalhamos com vários níveis de técnica em balé, preferimos usar a tradicional sapatilha de meia ponta para conforto e segurança das bailarinas.

O processo da autoscopia foi realizado três vezes. A primeira e a segunda videogravação foram feitas com uma câmera de primeira pessoa, ou seja, câmera fixada ao corpo do sujeito, neste caso, o partner (acampanhante, personagem masculino), com suportes de cabeça ( $1^{\mathrm{a}}$ videogravação) e ombro ( $2^{\mathrm{a}}$ videogravação). A câmera utilizada para a capturação das imagens foi um modelo Garmin Virb Elite. A terceira videogravação foi feita com a mesma câmera, mas com auxilio de um terceiro sujeito convidado do grupo de Pesquisa em Filosofia e Estética do Movimento (GPFEM), que simulava o campo de visão do bailarino, executando a coreografia atrás do mesmo.

Após a captação das imagens, a filmagem foi editada nos softwares de edição Garmin Virb Elite e iMovie. Para a edição, utilizamos um computador da marca Apple Mac OSX, versão 10.10, equipamentos pertencentes ao GPFEM. Além das câmeras e computadores, utilizamos o sistema de som estéreo modelo Fender 500, também de uso prioritário para as pesquisas do GPFEM.

Ressaltamos que os sujeitos pesquisados são do sexo feminino, neste caso, duas bailarinas (a fim de preservar a identidade das bailarinas, o critério adotado para identificá-las foi os codinomes - bailarina 1 e bailarina 2). O partner participou de todo o processo para dar suporte à coreografia, além de portar às câmeras que darão a visão análoga à bailarina durante o processo da filmagem.

Antes do inicio do projeto, as bailarinas foram convidadas a assinar o Termo de Consentimento Livre e Esclarecido (TCLE) para informar o intuito da intervenção, e propiciar maior segurança, legitimidade e credibilidade à pesquisa. Ressaltamos também a submissão e a devida aprovação pelo Comitê de Ética. Reiteramos, também, 
que as entrevistas transcritas para esse texto não foi alterada a fala das bailarinas, optamos por manter os vícios e as características da oralidade.

Após a edição do material, as bailarinas receberam o convite para, individualmente, responderem a duas perguntas, que foram gravadas para posterior análise dos pesquisadores. Antes de adentrarem à sala reservada para assistirem às filmagens, as participantes da pesquisa foram informadas que as imagens não haviam sido assistidas previamente e o que elas assistiriam seriam os segmentos completos, ou seja, sem o recorte de trechos da coreografia, captados pela câmera nas diversas posições já mencionadas, descarregados no computador por parte de um colaborador que auxiliou nesse procedimento e foi orientado a não dialogar conosco sobre as imagens.

Após o término da pesquisa, as imagens foram apagadas do disco rígido sem serem assistidas pelos pesquisadores. Nesse sentido, pensamos ter ficado expresso para os sujeitos da pesquisa que apenas eles viriam o conteúdo das imagens realizadas, ficando mais confortáveis para uma análise espontânea. Abaixo segue a pergunta realizada às participantes antes delas assistirem as imagens:

"Gostaria que você reproduzisse um feedback sobre sua performance, como você acha que dançou?"

Logo após assistirem, uma nova pergunta foi feita:

"Após ter assistido sua própria performance, gostaria que você produzisse um feedback sobre sua performance. Como você acha que dançou?

Após as entrevistas serem realizadas com as bailarinas, as respostas foram transcritas, para posterior análise pelos pesquisadores. Por se tratar de um estudo de cunho qualitativo, a preocupação estava centrada em realizar uma reflexão sobre o método autoscópico e não na produção de uma abordagem que buscasse evidenciar constatações de dados. Por essa razão, o trabalho optou por compor a sua amostragem com duas bailarinas e um bailarino (partner). Tal escolha caracteriza-se, como já informamos, como uma possibilidade de ampliação e abertura de um leque de reflexões pertinentes ao tema e não com o objetivo de produzir resultados, quantitativamente, efetivos.

\section{Sobre a aplicação do método}

Para a aplicação do método de pesquisa, foram feitas três filmagens:

$1^{\text {a }}$ Filmagem: com câmera de $1^{\mathrm{a}}$ pessoa (utilizaremos essa designação para indicar quando a câmera Garmin Virb Elite estiver 
fixa no corpo do partner acompanhante), fixada com auxilio de suporte de cabeça, simulando um olhar do tronco para cima da bailarina;

$2^{\mathrm{a}}$ Filmagem: com câmera de $1^{\mathrm{a}}$ pessoa, fixada com auxilio de suporte de ombro, simulando um olhar do tronco para baixo da bailarina;

$3^{\mathrm{a}}$ Filmagem: com câmera de $3^{\mathrm{a}}$ pessoa (utilizaremos essa designação para indicar quando a câmera Garmin Virb Elite estiver em outra pessoa que não seja o partner). Para essa filmagem, tivemos o auxilio de outro bailarino que também ensaiou a coreografia e a executou atrás do partner, aproximando a camera a ele, o que simulava seu campo de visão, porém recuado, de modo a enxergar o corpo todo da bailarina. Esse terceiro bailarino executou toda a coreografia junto, sem interferir na execução, mas mantendo o campo de visão.

Podemos observar também que a fixação das câmeras no partner parece não ter causado nenhuma interferência na performance dos sujeitos, uma vez que esses materiais foram projetados para serem utilizados durante o movimento, sendo de pequena dimensão.

$\mathrm{Na}$ exibição do vídeo para a bailarina, optamos que a mesma visse os três segmentos, na ordem em que os mesmos foram gravados, pois julgamos que qualquer tipo de edição poderia conduzir a opinião do sujeito da pesquisa. A organização do material foi feita por uma terceira pessoa do GPFEM, para que o entrevistador não visse o material.

Esse procedimento foi esclarecido aos sujeitos antes que eles assistissem aos vídeos. O procedimento buscou garantir tranquilidade aos sujeitos da pesquisa em emitir suas opiniões, pois eles sabiam que o entrevistador não havia visto as imagens. Tal atitude foi tomada, pois inferimos que caso os sujeitos soubessem que o entrevistador vira as imagens previamente as respostas dadas poderiam sofrer uma inclinação a dar opiniões que justificassem aquilo que o entrevistador viu.

Após a união dos três vídeos, sequencialmente, em um único clipe, cada sujeito foi encaminhado a uma sala privada na qual se encontrava um computador ligado a um monitor 29 polegadas de alta resolução. Os sujeitos foram instruídos que, após a saída do pesquisador da sala, apertassem a barra de espaço, o que daria inicio ao clipe. Também foi instruído que ao término do terceiro clipe, uma mensagem apareceria na 
tela ("fim do clipe") e que, assim, os participantes poderiam deixar a sala, encaminhando-se a sala vizinha, na qual ocorreria a entrevista.

\section{Resultados e Discussões}

Antes de uma análise do processo da autoscopia em si, faremos uma breve abordagem do rendimento das bailarinas e do partner nos dias de ensaio e filmagem. As bailarinas, por apresentarem um bom nível de balé clássico, não demonstraram dificuldades em apreender a coreografia e/ou executá-la. Os encontros para os ensaios e execussões do processo autoscópico foram feitos em dias diferentes, para ambas as bailarinas evitando assim uma eventual fadiga e desgaste do partner acompanhante, que foi o mesmo durante todo o transcorrer da pesquisa.

Em um primeiro momento, o partner acompanhante e a bailarina sentaram para assistir o vídeo do pas de deux. Vídeo esse disponível no site "Youtube", intitulado "Pas de Paysant". Após assistirem algumas vezes, os dois começaram os ensaios e depois de algumas repetições durante o mesmo dia, a coregografia estava pronta para a filmagem.

Vale salientar que as bailarinas perceberam uma grande diferença em executar o pas de deux sem a sapatilha de ponta. As mesmas revelaram que na ponta é mais "fácil", pois como a superfície de contato dessa sapatilha com o solo é menor, ela desliza com maior facilidade (facilitando os portês, pivots e giros) quando comparada a sapatilha de meia ponta, que apresenta maior aderência com o solo, dificultando os aspectos mencionados acima. Para tanto, foram feitas algumas adaptações, o que possibilitou a incorporação de novos movimentos, assim como a mudança e exclusão de outros.

\section{Sobre as primeiras impressões}

Quando falamos sobre as primeiras impressões, referimo-nos aos elementos que a bailarina revelou durante a primeira entrevista, ou seja, antes de assistir o seu processo autoscópico. Acreditamos ser pertinente realizar uma reflexão acerca das impressões separadamente, ou seja, impressões que as mesmas apresentaram antes e depois de se assistirem executando o pas de deux.

Em um primeiro momento as mesmas não oralizaram muito. Ambas as falas foram breves e demonstraram certa dúvida ou incerteza no que estava sendo dito. As bailarinas revelaram que estavam inseguras, pois haviam aprendido a coreografia há pouco tempo. Também revelaram a questão do "quicar" na coreografia, ou seja, durante a execução de alguns movimentos, principalmente os movimentos de pivots em que elas se desequilibravam da meia ponta e retornavam ao equilíbrio logo em seguida.

Os pontos revelados acima foram destacados antes das bailarinas se assistirem dançando. Em geral, elas revelaram estar satisfeitas com o que foi executado. 


\section{Sobre as segundas impressões e a autoscopia}

O primeiro elemento a ser destacado foi um ponto já revelado anteriormente que diz respeito ao tempo em que a coreografia foi executada. No seu discurso, a bailarina 1

revela que "Para responder a primeira pergunta foi mais difícil porque fazia muito tempo que a gente tinha gravado e eu não lembrava direito como a gente tinha dançado".

Pode-se observar que o tempo entre o processo de filmagem e o processo da autoscopia (processo em que a bailarina se assiste em ação) é importante no que diz respeito às memórias e às lembranças da bailarina que vão destacar pontos importantes para a pesquisa. Essa mesma bailarina revela que após ter se assistido, alguns fatores ficaram mais evidentes.

O primeiro ponto destacado pela bailarina 1 foi a "expansão" dos seus movimentos. Ela achava que estava dançando com movimentos mais longos e amplos, porém percebeu no vídeo que havia uma diferença no que tange a amplitude dos movimentos. A mesma destaca que: “...no vídeo dá para ver que não, que eu corto o movimento no meio, eu não deixo terminar...”. Quanto a isso, já podemos ensaiar uma primeira reflexão acerca da autoscopia quando se refere ao conceito de cinestesia e a capacidade de se desenvolver a partir do conceito uma noção espacial e dinâmica (MARZANO, 2007). Logo, isso implica na percepção do bailarino sobre o seu corpo no espaço e na cena.

Os pontos ressaltados pela bailarina em questão foram "cortar o movimento" e o "alinhamento do corpo". No primeiro caso, podemos interpretar como não deixar o movimento acontecer como um todo, cortando-o durante a sua ação. Esse mesmo aspecto nos remete a elementos cinestésicos, como a expansão e a amplitude. Uma vez que o movimento não está expandido, ele deixa de ser realizado em toda a sua complexidade acarretando em uma interrupta ou incompleta finalização.

No segundo caso, o alinhamento do corpo foi percebido em relação ao "penche" (movimento em que a bailarina se inclina para frente e levanta uma das pernas para trás). A bailarina percebeu que a relação ombro-quadril estava desalinhada neste seguimento. No seu relato, ela diz que sentiu essa questão, porém não imaginava o nível que estava. Tal aspecto ela só pôde perceber após assistir o vídeo.

A partir do momento em que a mesma se vê em cena, ela pode perceber questões que estavam sendo trabalhadas a partir da propriocepção, porém ao se assistir, ela percebe que estava enganada (como a questão da expansão e finalização dos movimentos). Em sua fala, ela revela que: "Quando foi filmado na cabeça, deu para ver muito a parte de cima, deu para ver como eu ficava travada, principalmente no pescoço 
e que minha cabeça não mexia direito, porém eu achava que estava "arrasando". (Bailarina 1).

Percebemos aqui que a questão de estar travada ou não realizar o movimento completamente só pode ser percebido pela bailarina após a mesma se assistir em cena. A diferença do que se "pensa estar fazendo" e o que "realmente está fazendo" é uma problemática pertinente a muitos bailarinos.

Uma vez que sem a utlização dessa metodologia de análise o recurso de retorno da performance do bailarino vem por parte do ensaiador e/ou coreógrafo. Logo a interpretação sofrerá muita influência por parte dessa figura externa e, assim, impossibilitará essa análise íntima e introspectiva (proposta pelo método da autoscopia), do próprio bailarino.

Ressaltamos um ponto positivo acerca da autoscopia, uma vez que o próprio autor da ação (bailarino) passa a ser o sujeito que analisa sua performance, percebendo pontos que outrora passaram despercebidos (pelo coreógrafo, ensaiador ou partner), facilitando o processo de correção, tanto no que diz respeito à técnica, que neste caso é a técnica clássica, quanto à expressividade.

Ainda acerca da autoscopia, em um contexto profissional esse recurso torna-se válido e efetivo quando comparado ao numero de bailarinos a serem corrigidos e orientados por um único coreógrafo e/ou ensaiador. Ao se assistir em cena esse bailarino consegue perceber seus próprios erros e desenvolver assim uma capacidade de autoanálise e auto-feedback proposto pelo método aqui apresentado.

\section{CONSIDERAÇÕES Finais}

Há uma grande dificuldade do próprio bailarino se tornar o sujeito da sua própria análise, aquele que realiza um auto-feedback no que diz respeito às questões técnicas e expressivas da sua dança, pois como já mencionamos esse atributo de correção e análise é, prioritariamente, de responsabilidade do ensaiador ou coreógrafo.

Por esse questionamento, acreditamos ser de grande valia aproximar a técnica de pesquisa chamada autoscopia. O campo da educação já se apropriou dessa metodologia e a utiliza para a reflexão e análise das professoras que se filmam dando aula. Pensamos que essa técnica possui uma relevante importância e pode colaborar em relação à problemática dessa pesquisa no campo da dança.

Após ser apresentada a hipótese e feita a aplicação do método e o posterior colhimento e análise dos dados, podemos inferir que, dentro da perspectiva proposta pelo processo da autoscopia no campo da dança, a aproximação torna-se válida e efetiva 
como recurso de autoanálise e auto-feedback para os sujeitos pesquisados. Após se assistir em cena, a bailarina consegue ampliar a percepção dos seus movimentos, e a partir disso, tomar conscientização dos seus gestos e ações durante a sua performance.

Durante o período da pesquisa, fizemos diversos levantamentos bibliográficos sobre o assunto para chegarmos a um método de intervenção que contempla a dança e a autoscopia apresentou-se como um promissor recurso de autoanálise e auto-feedback para o bailarino. No que pode ser observado durante o processo, tanto na aplicação do método, quanto na entrevista e análise por parte dos pesquisadores, a autoscopia mostrou-se uma proposta válida e efetiva, que pode trazer grandes contribuições ao campo da dança, pois demonstrou possibilidades de ser explorado e utilizado na formação reflexiva de professores (SADALLA, 2004). Ao trocarmos a palavra professores por bailarinos, podemos inferir, após nossa investigação, que a passagem talvez seja válida. Uma vez que o sujeito passa a ser crítico e reflexivo acerca daquilo que faz.

A partir do momento em que o sujeito adquire uma maior consciência (depois de se assistir em cena pelo processo autoscópico) dos seus gestos e ações, inferimos que a expressividade do gesto pode vir a ganhar mais potência, assim como a expressividade da ação ganha mais força. A bailarina em cena, por ter se visto dançando, desenvolve a oportunidade de uma expressão mais nítida desse gesto, o que pode vir a melhorar futuramente sua qualidade técnica e expressiva durante suas performances.

Ao propormos o método da autoscopia, não estamos descartando a função do ensaiador e/ou coreógrafo durante o processo de criação e ensaio. Acreditamos que o trabalho por eles desempanhado é de suma importância para a produção do espetáculo, mas pensamos na dimensão complementar e colaborativa que a metodologia apresentada nesse texto trará para o seu trabalho. Ademais, a proposta do método poderá ampliar as possibilidades cinestésicas e proprioceptivas para uma consciência ampliada do bailarino sobre seu próprio gesto e a sua performance (por meio do auxilio visual da filmagem autoscópica), fazendo com que o mesmo perceba, sem os apontamentos externos, feitos pelo ensaiador, seus próprios erros, corrigindo-os e tomando consciência do seu próprio corpo e movimento.

\section{REFERÊNCIAS}

CAMINADA, Eliana. Historia da dança: evolução cultural. Rio de Janeiro: Sprint, 1999.

COHEN, Selma Jeanne. International enciclopédia of dance. Oxford: Oxford University Press, 2004. 
FERREIRA, Manuel Domingos Casinhas. A importância da cinestesia na aprendizagem e desempenho das tarefas motoras. Educação \& Comunicação, n. 3, p. 26-33, jun. 2000),

FERRÉS, Joan. Vídeo e educação. Porto Alegre: Artes Médicas, 1996.

GRESKOVIC, Robert. Ballet 101: a complete guide to learning and loving ballet. Minnesota: Hal Leonard Books, 2005.

LINARD, Monique. Les effects Du feedback par television sur le processus enseignerapprendre en situation de groups-classe. Bulletin de Psychologle, v. 28, n. 316, p. 9-12, 1974.

MARZANO, Michela. Dicionário do corpo. São Paulo: Loyola, 2007

NAUTRE, C. Etude sur l'utilisation de l'autoscopie video en formation permanente au Groupe Esc Lyon. In: Cycle de Management des Ressources Humaines à I'institut de Gestion Sociale de Lyon, 3., Stage Février/Mars (Spéciel). Lyon, France, 1989, p. 1-41. (Mimeo).

SADALlA, Ana Maria Falcão de Aragão; LAROCCA, Priscila. Autoscopia: um procedimento de pesquisa e de formação. Educação e Pesquisa, v. 30, n. 3, p. 419-433, set./dez. 2004. 

ERROR: syntaxerror

OFFENDING COMMAND: --nostringval--

\section{STACK :}

/ Title

()

/ Subject

(D:20170814161331-03'00')

/ModDate

( )

/Keywords

(PDFCreator Version 0.9.5)

/Creator

(D:20170814161331-03'00')

/CreationDate

(dulce)

/Author

-mark- 